\title{
THE FACTORS THAT GOVERN THE STABILITY OF THE SPINE
}

\author{
By Donald Munro, M.D., F.A.C.S. \\ Milton, Mass., U.S.A.
}

As far as I have been able to learn, the factors that govern the stability of the spine have never been subjected to analysis. Inasmuch as the cervical is its most mobile part and has the greatest need for stability, and since it could be handled more easily than any other, it was chosen for appropriate study. However, because of the differences between the atlanto-axial complex and the rest of the bones, the detailed analysis was confined to the five vertebrae below that level.

Method. Through the courtesy of the Professor of Anatomy at the Harvard Medical School, I was provided with a specimen of the seven disarticulated but matching cervical vertebrae. I wired the seventh to a block of wood with its spinal canal centred over a hole in the wood. The rest were placed one above the other, on top of the seventh. A moderately stiff rubber was threaded through the canals of all. The lower end of the tube passed through the hole in the wood and was split into four tails which were tacked to the under surface of the block. The upper end was pierced by an open loop of wire so adjusted that its ends hooked over the anterior arches of the atlas and axis, at a level that would stretch the tube moderately. This facilitated handling and duplicated, to some degree, the gravitational effect and superimposed weight of the skull.

The odontoid process was wired in its normal relationship to the arch of the atlas so that the two bones could be handled as a unit.

All the bones were thus stabilised sufflciently to make it possible to maintain them in their relative positions and, at the same time, not to interfere with their freedom of action. The opposing surfaces of the articular facets and the posterior transverse tubercles were painted black and white respectively to permit photographic identification.

Observations. The first set of observations were made with the bones in the condition described above and without further support.

The second were made with the fourth, fifth and sixth vertebrae wired together through drilled spinous processes as advised by Rogers (1942), or attached to one another by a simulated bone graft. Free sponge-rubber discs, so cut as to represent 40 per cent. of the total length of this part of the spine, were placed between the adjoining vertebral bodies, and positional manipulations were carried out in both instances with wiring and graft both absent and present.

Thirdly, the sponge-rubber discs were glued to the upper and lower surfaces of the adjoining bodies and the above observations repeated.

Fourthly, following this, a piece of 'elastoplast' (elastic adhesive tape) was applied against the anterior and posterior surfaces of the vertebral bodies and discs after the rubber tubing has been removed from the spinal canal, and similar observations were again made.

As a fifth and final step, the spinous processes were united by a simulated interspinous ligament and ligamentum nuchae, both made of elastoplast, and note taken of any added stability that accrued from them.

These various findings that related to the stability and mobility of this part of the spine and its units, as made under these various conditions, were recorded in terms of shape of the curvature, movements of the bodies, discs, lateral processes, articular facets, laminae and spinous processes. The various changes were also photographed.

Anatomy. The standard osteological descriptions of the spine and its ligaments was written by Thomas Dwight in I906. No essential changes have been 
made in them since then, but it is profitable to review certain points because of their intimate association with the problems of stability.

The Normal Curvature of the Sfine. Dwight, quoting Humphry (1906), states that the approximate, mean, normal shape of the cervical and other curves is one which permits a plumb-line, dropped from the centre of the odontoid proce s, to pass through the bodies of the second and twelfth thoracic and the inferior ang le of the body of the fifth lumbar vertebrae. Between its two extremities, this line will pass just behind the posterior surface of the seventh cervical body. The apex of the cervical part of this curve will be anterior to and at a point about opposite the fourthfifth disc. This curve tends to flatten out below its apex. This is the only method I have been able to find in any of the standard anatomies, by which the normal curve can be determined. There seems to be no reason to doubt its accuracy.

The Bones. The atlas, axis and skull form a functional unit by themselves and are not considered in this paper. The rest of the cervical vertebrae show the following noteworthy points: the spinous processes do not normally impinge on one another; however, they do overlap and conceal the interlaminal spaces from sight; the transverse processes are bifid at their free ends; these form the anterior and posterior transverse tubercles; the posterior, which is the more important from the points of view of stability and motion, ends in a flattened, nearly vertical projection which is longer but smaller than the anterior.

Except for the presence of the costal processes in the thoracic portion, it and the lumbar sections have no other noteworthy characteristics.

The Articular Facets. These are placed at the outer ends of adjoining laminae. The upper of each pair faces upward and backward and the lower, downward and forward, each pair forms one of the true gliding joints (arthrodia), being lined by hyalin cartilage, and the whole joint is surrounded by a ligamentous capsule.

The Unco-vertebral Foint of von Luschka (1858) and Fraser (1958). This is said to be formed by the approximation of a part of the upper posterior edge of one cervical body to the adjoining costal process or the body next above. It is probable that the importance of this hypothetical joint has been much over-rated and that it is significant only in the presence of spondylosis cervicalis.

The Ligaments. The most important are the three that connect the vertebral bodies. All resist rotation, flexion and especially extension. They are the anterior and posterior common spinal ligaments and the intervertebral discs. Of the first two, both of which extend from the occiput to the sacrum and are applied respectively to the anterior and posterior surfaces of the vertebral bodies and intervertebral discs, the anterior is the strongest, the most closely attached and the more important. The posterior is the weakest of the three, the most loosely attached and the least effective. The third is the most important and effective of all is the intervertebral discs. They act as ligamentous, compressable, elastic connections between all the vertebral bodies.

The cervical discs are said to form 40 per cent. of the length of the cervical spine (Dwight, I906) and the lumbar discs to be individually able to successfully resist direct pressure of I600 pounds (Bradford \& Spurling, I945). All are compressable and so firmly attached to the vertebrae between which they rest, that they will rupture before this attachment will part.

There are also other but less vital ligaments such as the ligamentum nuchae in the cervical region and the interspinous, interlaminal and capsular ligaments at all levels. All resist forcible flexion and rotation. 
Another is the ligamentum flavum which has attained a certain fame because it has been said to fold on itself and remain in that position and thus compress the cord. It has also been considered by some to be thereby the cause of cord symptoms that occur in subluxations. Certainly it has been only rarely described in this position in life and has been seen only once at operations at any level of cord injury in my series of about 600 cases. It probably serves only as a protection to the cord in the canal.

All spinal ligaments, except the intervertebral discs which are compressible, are elastic in that they possess the ability to stretch and lengthen or contract when subjected to chronic strain. In acute strains, however, this ability is greatly curtailed except in the case of the ligamentum flavum. The others tear or are separated from their attachments.

The Muscles. The mass of paravertebral muscles that supplement the ligaments in the cervical region are especially noteworthy. Here, there are at least 20 pairs of voluntary muscles. They are inserted in the bones and ligaments and arise from them and from fascial planes. They have segmental as well as more extended origins and insertions and, like the other parts of these muscles, can respond to appropriate stimuli as a single unit or as parts of the same unit. Their nerve supply comes, in part, from branches of the cervical plexuses, and for the rest by way of the segmental distribution of mixed spinal nerves. This is an important consideration, particularly in the treatment and prognosis of cervical spine and cord injuries. The functional anatomy and clinical significance of these muscles has been well delineated by Perry and Nickel (1959) in their studies of severe cases of high poliomyelitis and the resulting paralyses.

The lower paraspinal muscles have, in general, the same anatomy and an analagous nerve supply in accordance with their level. As a group, however, they are more characterised by their strength than by their ability to promote free action in all directions as the cervical group does, even though this latter function is by no means lacking at any level.

The Stability of the Spine in the Absence of Disease or Injury. Detailed observations were made only on the cervical spine because of the reasons given above. In general, however, the evidence indicates that the conclusions can be accepted as appropriate for other levels as well.

The Stability of the Unsupported Bones. With normal, disarticulated, matching, cervical vertebrae set up in normal relationships but without any substitute ligamentous support, it is at once apparent that stability is totally absent. With the centre of gravity in neutral position and with the spine held erect manually, there is a greater tendency, however, for it to collapse and disintegrate in the extended position (fig. I $a$ ) but a shift of the centre of gravity anteriorly is accompanied at once by an equal collapse and disintegration in flexion (fig. I $b$ ) unless supported. No stability, therefore, is inherent in the bones themselves.

The Stability of the Bones with the Discs in Place but Loose. With the discs in place but not glued to the vertebral bodies, the situation is not materially different. The curve is almost normal if the bones are manually supported, but disintegrates when this additional support is removed. The facets are in nearly normal position. Forced flexion anteriorly tends to spew out the apical disc posteriorly and forced extension does the same thing anteriorly (fig. 2). There is no stability provided by added but unattached discs. 
The Stability of Either Wired or Fused Bones. The only change from the instability and disintegration present in the first and second observations was a lack of mobility between the wired or fused vertebrae. This local immobility did not affect the rest of the bones either above or below the immobilised area. The latter collapsed and disintegrated as before in the absence of artificial ligaments or the presence of unattached discs. The addition of wiring or simulated fusion adds no stability but only local immobility in the absence of attached ligaments.

The Stability of the Bones with the Discs Fastened in Place. These observations were carried out both in the absence of and with wiring and artificial fusion, but with the discs properly fastened in place.

A most dramatic change in stability took place. Disintegration was prevented; the curvature, except for slight extension, was normal; the motions were free; and

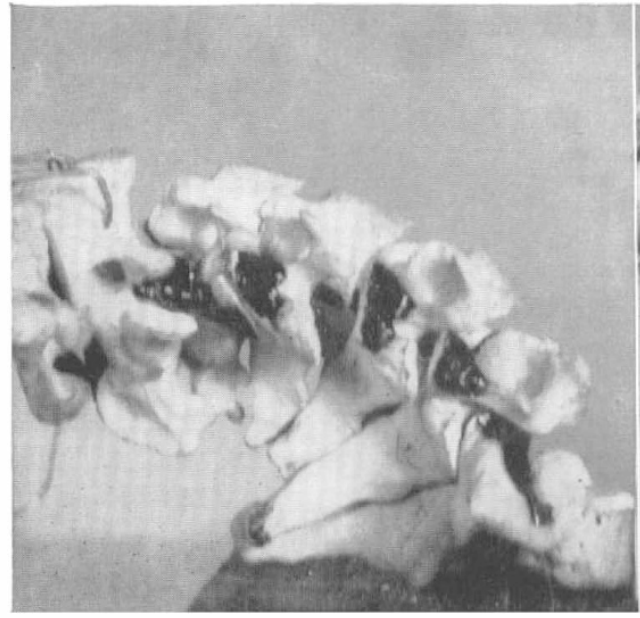

(a)

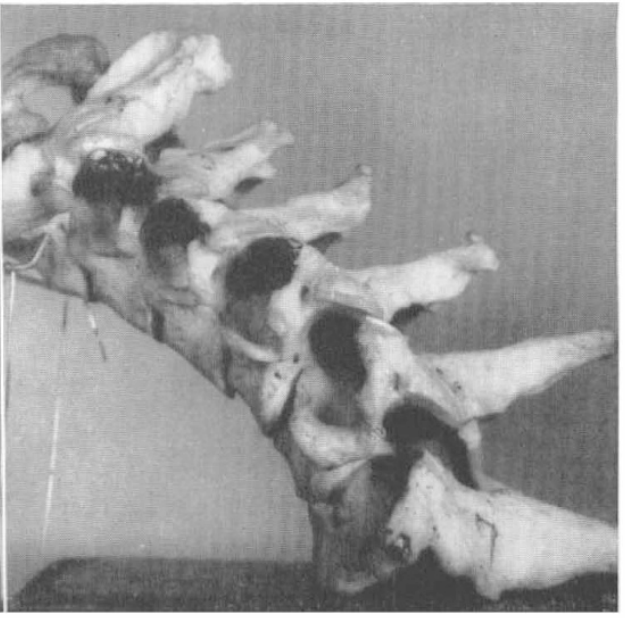

(b)

(a) Disintegration of the cervical spine, in the absence of ligaments, in extension.

(b) Disintegration of the cervical spine in flexion in the absence of ligaments.

the bodies as well as the spinous processes, the laminae and the posterior tubercles were all in normal positions. Forced flexion of the spine caused compression of the anterior and spreading of the posterior edges of the discs, whereas forced extension no longer caused spewing of the discs anteriorly as happened with the unfastened discs.

Measurement by a spring balance of the force necessary to flex the spine to the point where the $4 / 5$ facets were just short of dislocation, demonstrated that io pounds were now required to accomplish this degree of flexion, and that disintegration could not be produced. In contrast, complete disintegration in either direction prior to this fixation of the discs had been accomplished by no more than a fingertip push. Major stability is provided by the presence of attached intervertebral discs.

The Addition of Elastoplast Anterior and Posterior Common Spinal Ligaments. This change eliminated any remaining slight instability and changed the shape of 
the curve to normal (fig. 3). Forced extension and flexion were now possible only with the application of 30 pounds pressure. Complete stability is provided by the addition of the common spinal ligaments to attached intervertebral discs.

The Addition of Interspinous Wiring and Simulated Interlaminal Fusion. These additions, made with the discs in place and fastened, as well as the common spinal ligaments, added nothing to the stability which was already present. Immobilisation was produced but that had no further influence on the stability that had been already produced on other bones by the discs and common spinal ligaments.

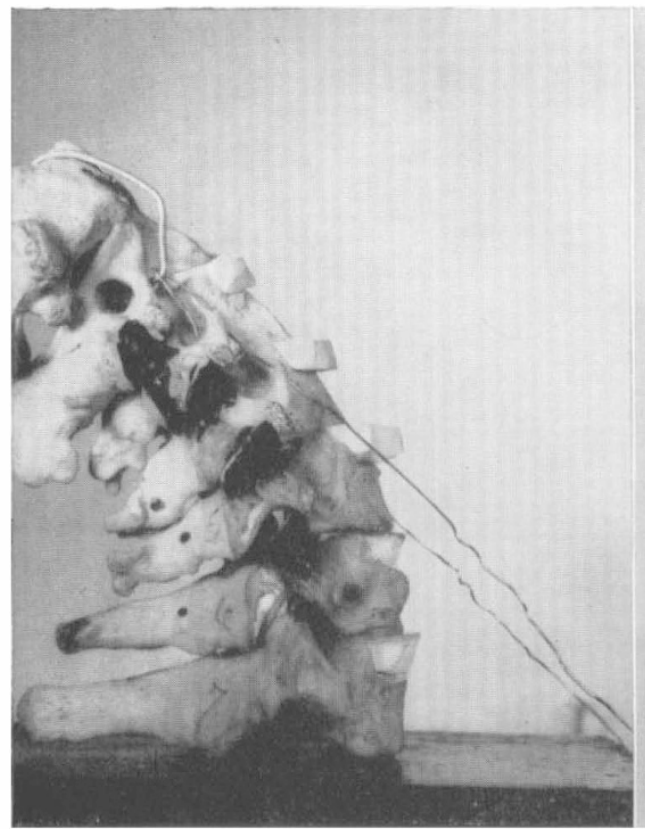

FIG. 2

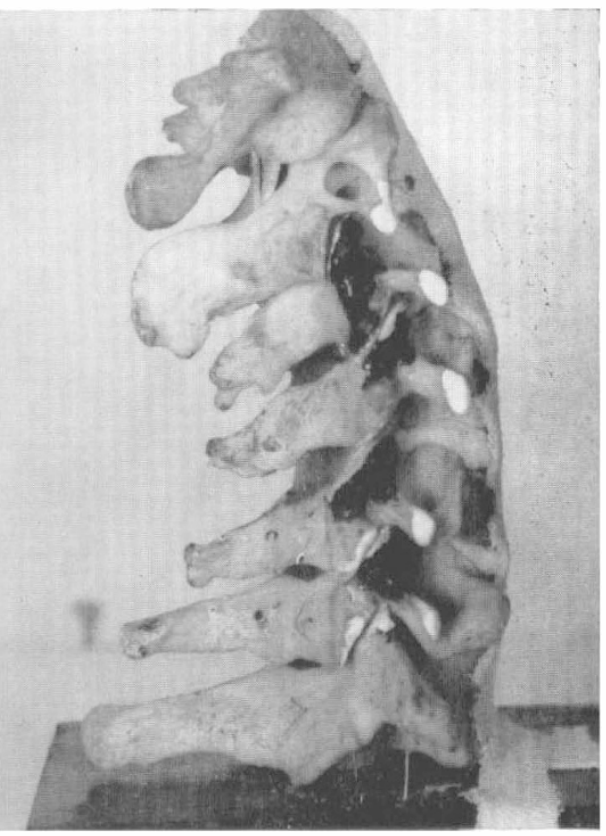

FIG. 3

FIG. 2.-Protrusion of unattached discs caused by extension of the cervical spine in the absence of ligaments.

Fig. 3.-Normal cervical curve according to Dwight, as tested by a plumb-line, after the discs and common spinal ligaments have been fastened in place and the rubber tubing removed from the canal.

Conclusions. It is obvious from these observations that cervical spinal stability is chiefly dependent on the attached intervertebral discs and is brought to perfection by the addition of anterior and posterior common spinal ligaments. It is equally obvious that, in the absence of the discs and the spinal ligaments, the bones, of themselves, have no inherent stability at all. It is apparent that neither the wiring nor the fusion or adjoining vertebras produces any stability, even if three are included, except that associated with immobility between the centre vertebra and the ones next above and below it. Moreover, the stability of the rest of the spine is in no way improved by such wiring or fusion and, except locally, resides, when present, in the ligaments and their attachments to the various bones. 
Destructive Procedures. Effect of the Removal of One Cervical Disc. If any particular disc is removed from between any two contiguous vertebrae, the stability of the spine remains normal but the shape of the curve becomes more acute, and the positions of the spinous processes as well as the relations of the articular facets are altered.

If the disc is removed through an anterior approach, the disalignment of the vertebrae subjects adjoining discs to compression and distortion. In addition, the necessary division of the anterior common spinal ligament weakens those parts of it that are above and below its transection at the point of the disc removal. Loss of support and distortion of the spine follow. The same holds true to a lesser extent

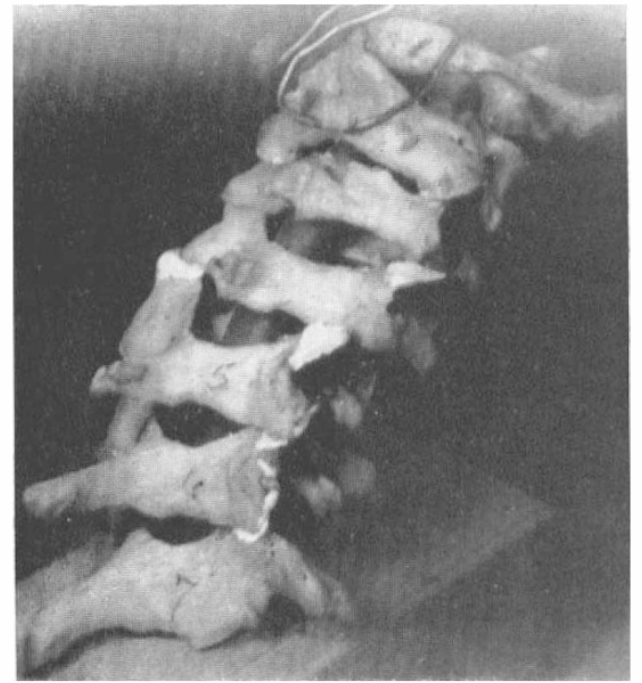

FIG. 4

Note the unilateral subluxation on the left and the unilateral dislocation on the right between the articular facets of the fourth and fifth cervical vertebras. when a disc is removed by way of a posterior approach through a transected posterior common spinal ligament. This is less damaging, however, because of this ligament's comparative weakness, looser attachments and smaller amount of support.

Increase in the Length of the Cervical Spinal Canal. Any curved tube that is mobile is so because of the ability of its walls to either lengthen or shorten when the shape of the curve is changed. Because of this, appropriate measurements were made along the posterior surface of the anterior wall of the cervical spinal canal with and without an added subluxation or dislocation of the articular facets but with the discs and the common spinal ligaments in place. It was not possible to make similar measurements on any other part of the canal, and it is not known whether those that were obtained apply to other levels, but there is no reason not to believe that the same results, although to a lesser degree, will follow.

The anterior inner wall of the canal without change in the position of any facets and with the spine in a neutral, normal position, was six inches long. With the spine forceably flexed, however, to a point just short of producing bilateral subluxation of the $4 / 5$ articular facets at the apex of the induced curve, the canal was increased in length by $\mathrm{I} \frac{1}{8}$ inches. With the spine in extension to the point where further such motion was impossible, the original length was increased by $\frac{1}{4}$ inch. If one pair of articular facets were dislocated (unilateral dislocation) and its fellow put in a position just short of dislocation (unilateral subluxation), the rotation that resulted increased the canal-length by $\frac{5}{8}$ inch (fig. 4).

Because the contained spinal cord is fastened at both ends of the canal, it is stretched to a varying amount, but in accordance with the lengthening of the canal and the restricting influence of the roots and the dentate ligaments and their imposed limitations, causing damage to the cord, but not necessarily accompanied by 
any bone injury. This describes the effects of either a subluxation or a dislocation of the facets as detailed above.

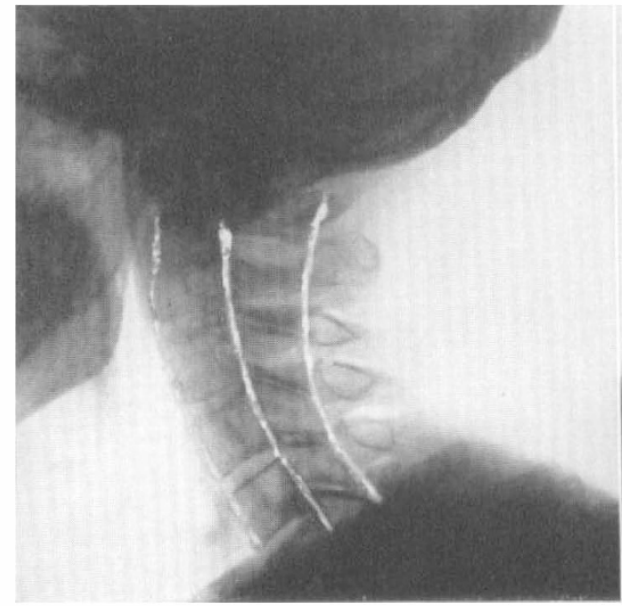

(a)

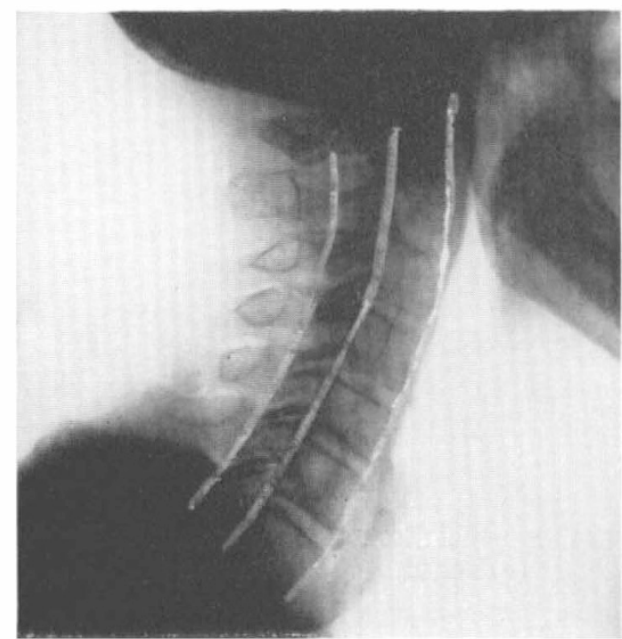

(c)

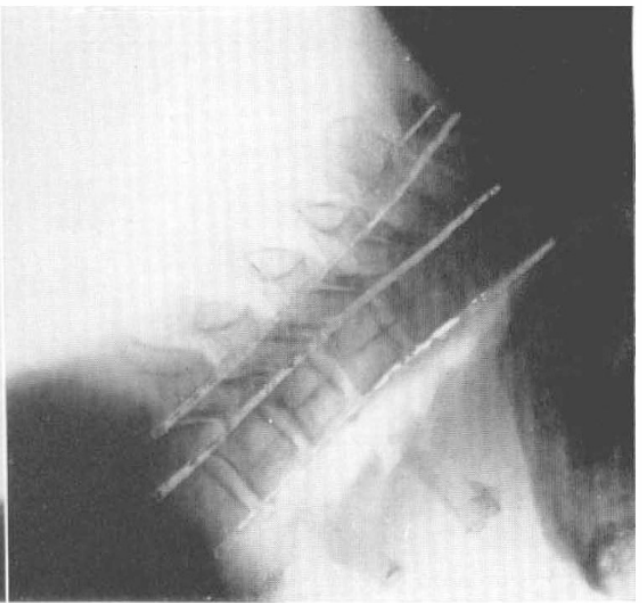

(b)

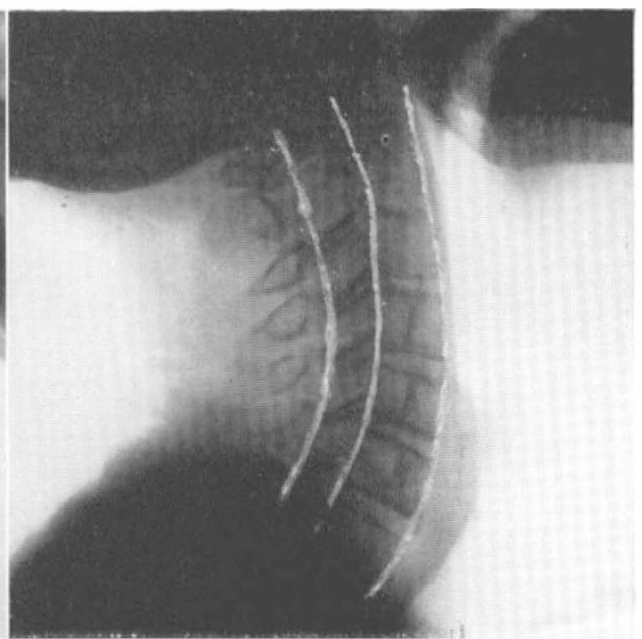

(d)

FIG. 5

Normal adult cervical spine shown: $(a)$ in neutral, $(b)$ in flexion with the chin on the chest, $(c)$ in flexion with the chin in neutral position and $(d)$ in extension.

Motions in the Normal Spine. (The illustrating X-rays were all made of the spine of a normal man, 2I years of age and free of previous injury or disease.) In the cervical spine, flexion can take place at two levels and depends for its location on the approximation of the chin to the anterior surface of the neck. If it is close, the flexion occurs chiefly between the third and fourth vertebrae and the rest of the spine 
becomes straight and without any curve (figs. $5 a$ and $b$ ). Rotation is not present and any extension at other levels is impossible. With the chin in a normal neutral position, however, flexion is centred at the approximate level of the $4 / 5$ disc and the

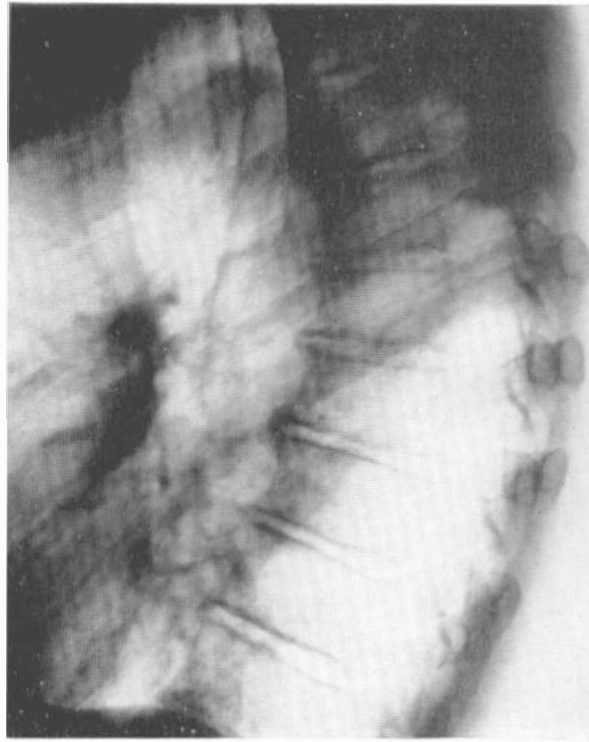

(a)

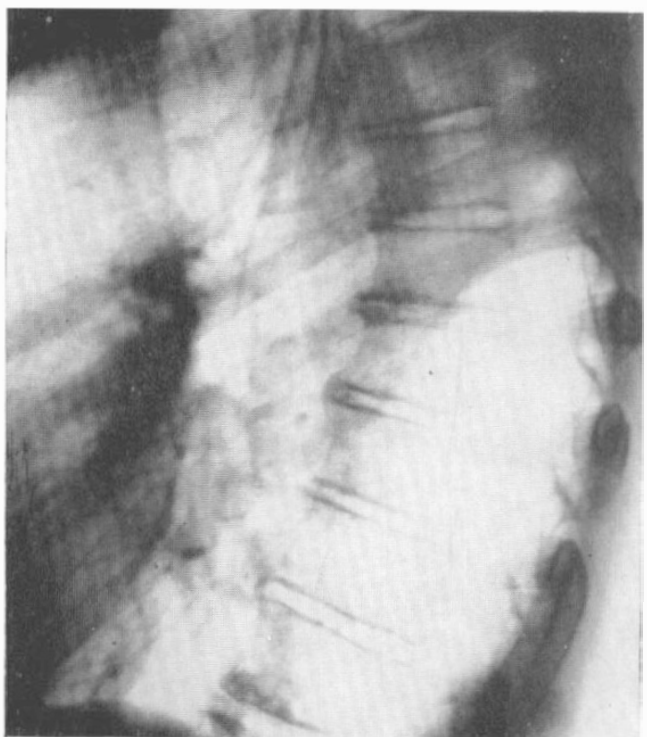

(c)

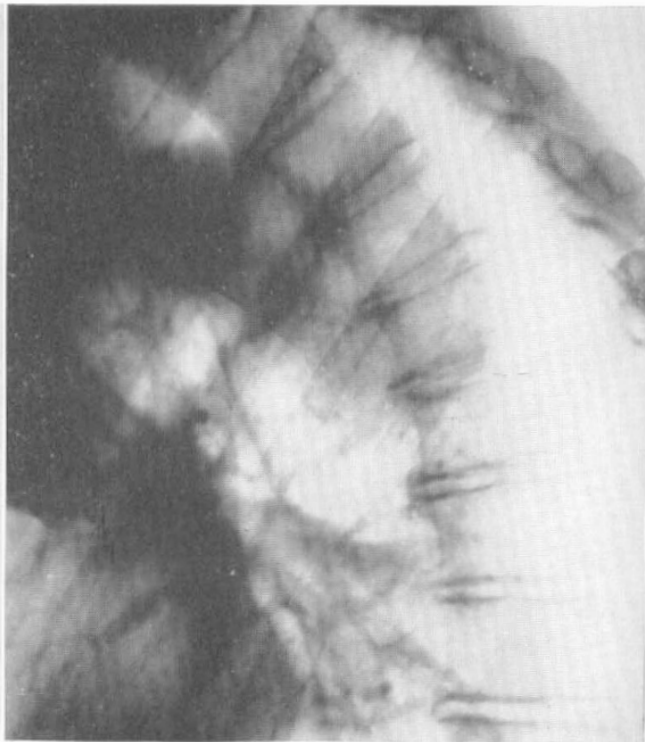

(b)
FIG. 6

Normal thoracic spine shown by X-ray in (a) neutral, (b) flexion and (c) extension.

upper portion does not change its position. Flexion, extension and rotation are now free up to the limits of normal, the motions taking place between the fourth and seventh vertebras, with the greatest amount at the $5 / 6$ level (figs. $5 c$ and $d$ ). 
Lateral motion is associated with rotation and involves all vertebrae in both motions. Pure lateral motion without rotation is minimal.

Motion in the thoracic spine under normal conditions and from a practical aspect, is almost non-existent. The function of this part of the spine is to remain fixed and stable (figs. $6 a, b$ and $c$ ).

Motion in the lumbar spine is also limited but is slightly less so than in the thoracic. It is permitted by the compressability of the discs and consists of flexion, extension and rotation. The last is minimal and is controlled, in part, by the articular facets.

Motion is provided at all levels by the paraspinal muscles. If any significant paralysis of these muscles develops following disease or as caused by traumatic denervation, the ligaments stretch, the bones gradually lose their apparent stability and the spine slumps in flexion in the cervical and less frequently in the thoracic and lumbosacral areas. Instability and collapse in flexion follows.

Forced Extension and Flexion. Forced extention is prevented by overlapping of the spinous processes; by contacts made between the posterior tubercles and adjacent articular facets and by the jamming of all the local laminae by the forcible piling up of each pair on top of the next.

Forced flexion is prevented by the appropriate ligaments. The most effective are the two common spinal ligaments and the discs. The next most effective is the group of interspinous and interlaminal ligaments. The capsular offer no effective resistance except against rotation.

The Lumbar Facets. In addition to the strength of the vertebrae and the shape of the curve, the lumbar facets are generally credited with more than usual stabilising and restrictive effect on any motions. My experience has not supported this theory. For example, a free removal of lumbar facets as a part of any operative procedure has been carried out without symptomatic after-effects whenever it was thought necessary or helpful. No acute or chronic disability was ever demonstrable later in any such case either while the patient was hospitalised or later.

In connection with this, experiments were carried out to determine the breaking strength of each member of a pair of facets. It was demonstrated that, in cadavers, this was in the neighbourhood of 50 pounds as measured by the pull registered on a spring balance.

The Atlanto-Axial Complex. In the course of the previous observations it was observed that this complex was stable on the third vertebra as long as a disc remained between this and the second vertebral bodies, and, like others, was attached to both. However, when the wire that had been put around the odontoid process to fasten it to the atlas was removed, there having been no other ligaments added at this level, the atlas had no stability whatsoever and, regardless of the stability of the rest of the spine, disintegrated completely as far as this section was concerned.

\section{SUMMARY}

The stability of the spine depends on its ligaments and especially on the intervertebral discs and the common spinal ligaments.

The bones, whether individually or as a group, contribute stability to the spine only by acting as anchorages for the ligaments. 
Fixation of the bones by wiring, plating or fusion with a simulated bone graft, does no more than immobilise the united bones.

Fusion is most effective as a replacement for the flaccid muscles and stretched ligaments in wide-spread paraspinal muscular paralysis. It should not include the use of foreign bodies, nor should the removal of a normally placed disc be countenanced, especially when the latter is to be excised through a transection of the anterior common spinal ligament.

\section{RÉSUMÉ}

La stabilité de la colonne vertébrale dépend de ses ligaments, surtout des disques intervertébraux et des ligaments spinaux communs antérieurs et postérieurs. Les vertébres, soit individuellement ou comme groupe, contribuent à la stabilité spinale seulement en tant qu'insertions ligamentairs.

La fixation des vertèbres par cerclage, plaque ou greffe ne fait que les immobiliser, ceci d'une façon effective, compensant la paralysie des muscles para-spinaux, à condition qu'il s'agisse d'une fusion inter-laminaire unissant au moins 6 vertèbres en excluant l'usage des corps étrangers, l'évacuation de disques intervertébraux normaux et enfin, rejetant toute méthode qui consisterait à diviser le ligament spinal commun antérieur.

\section{ZUSAMMENFASSUNG}

Die Stabilität der Wirbelsaüle hängt von ihren Bändern und besonders den Zwischenwirbelscheiben $a b$.

Die Wirbelknochen, ganz gleich ob individuell oder als Gruppe nehmen an der Erhaltung der Stabilität nur als Anker für die Bänder teil.

Fixierung der Wirbelknochen mittels Drahê, Mietallplatten oder Fusion mit Knochenplastik bezweckt nur die Immobilisation der vereinigten Knochen.

Fusion ist sehr wirkungsvoll als Ersatz für die schlaffen Muskeln und überdehnten Bänder in ausgedehnter paraspinaler muskulärer Lähmung. Die Operation sollte die Anwendung von Fremdkörpern vermeiden, ferner ist die Entfernung einer in normaler Position befindlichen Zwischenwirbelscheibe abzulehnen, insbesondere wenn zu ihrer Entfernung die Durchtrennung des vorderen gemeinsamen spinalen Ligaments erforderlich ist.

\section{REFERENCES}

Bradford, F. Keith \& Spurling, R. Glenn (1945). The Intervertebral Disc. 2nd Ed. Springfield, Illinois: C. C. Thomas.

Dwight, Thomas (1906). In Human Anatomy. Ed. Piersol, G. A. Pp. 103, 138, 133. Philadelphia: J. B. Lippincott.

Frazer, J. E. (1958). Anatomy of the Human Skelton. 5th ed. Ed. Breathnach, A. S. London: J. \& A. Churchill.

Perry, J. \& Nickel, V. L. (1959). F. Bone ft. Surg. 4IA, 37.

Rogers, W. A. (1942). F. Bone ft. Surg. 24, 245.

von Luschka, H. (I858). Die Halbgelenke des menschlichen Korpers. Berlin: Reimer.

\section{CORRIGENDA}

I. References to paper by Lionel Wolman, M.A., M.D., Ph.D., M.R.C.P., D.P.M., Vol. 2. No. 4, p. 226, should read:

Line 7: BRUNN, F. (1932). Wien. klin. Wschr. 45, I425.

Line io: Cameron, G. R. \& Sheikh, A. H. (I95I). F. Path. Bact. 63, 609.

Line I2: CAMPBell, G. S., HadDY, F. J., AdAMS, W. L. \& Visscher, M.B. (I949) Amer. F. Physiol. 158, 9.

Line 22: Harrison, W. \& Liebow, A. A. (1952). Circulation, 5, 824.

Line 35: Sarnoff, S. J. \& Berglund, E. (1952). Amer. F. Physiol, 170, 588.

2. The authorship to paper "Subarachnoid Phenol Block in the Treatment of Pain and Spasticity", Vol. 3, No. 2 should read:

S. Allen Schmidt, M.D., Harvey, D. Cain, M.D., and Sedgwick Mead, M.D. 